\title{
Effect of airflow interaction in the breathing zone on exposure to bio-effluents
}

Bivolarova, Mariya Petrova; Kierat, Wojciech; Zavrl, Eva; Popiolek, Zbigniew ; Melikov, Arsen Krikor

Published in:

Building and Environment

Link to article, DOI:

10.1016/j.buildenv.2017.08.043

Publication date:

2017

Document Version

Peer reviewed version

Link back to DTU Orbit

Citation (APA):

Bivolarova, M. P., Kierat, W., Zavrl, E., Popiolek, Z., \& Melikov, A. K. (2017). Effect of airflow interaction in the breathing zone on exposure to bio-effluents. Building and Environment, 125, 216-226.

https://doi.org/10.1016/j.buildenv.2017.08.043

\section{General rights}

Copyright and moral rights for the publications made accessible in the public portal are retained by the authors and/or other copyright owners and it is a condition of accessing publications that users recognise and abide by the legal requirements associated with these rights.

- Users may download and print one copy of any publication from the public portal for the purpose of private study or research.

- You may not further distribute the material or use it for any profit-making activity or commercial gain

- You may freely distribute the URL identifying the publication in the public portal 
Effect of airflow interaction in the breathing zone on exposure to bio-effluents

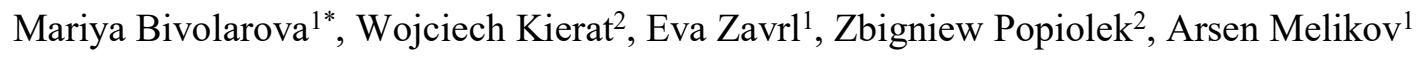

${ }^{1}$ International Centre for Indoor Environment and Energy, Department of Civil Engineering, Technical University of Denmark

${ }^{2}$ Silesian University of Technology, Department of Heating, Ventilation and Dust Removal Technology, Poland

*Corresponding author's e-mail address: mbiv@byg.dtu.dk 


\section{Introduction}

The human body emits particles (bio-aerosols) and gases (bio-effluents). Human respiration activities (exhalation, coughing, sneezing) generate bio-aerosols that may carry viruses and bacteria [1] that may cause airborne transmission of infection in confined spaces [2]. Human body movement and friction between the clothing and the skin generate skin flakes that contain a wide variety of contagious pathogens [3]. The flakes can be transported by air, inhaled and infect other occupants. The bio-effluents are volatile and non-volatile organic compounds that may be detected by the human olfactory system as odours. Oral cavity, armpits, groin, head and feet are the sites where bio-effluents are mostly generated [4]. Sweating is important for human body thermal regulation. The sweat is accumulated by the skin microbiome and further metabolised into volatile and non-volatile odours compounds [5]. The odour emanating from the human groin area is from the skin and from human excreta (e.g. urine). The compounds found in human excreta are acids, ammonia, sulphur, nitrogen compounds and other volatile metabolites [4]. Flatus also contributes to body odour and smells mainly because it contains a combination of volatile sulphur compounds [6]. Ozone reacts readily with squalene (found in skin oil) on occupants' skin, clothing and hair [7-9]. The reactions produce sub-micron particles and volatile products which may cause headaches, eye and respiratory irritation and increased susceptibility to respiratory illness [10]. Studies report that dermally-emitted pollutants have a higher odour intensity compared to the pollutants in exhaled air and may have a negative impact on occupants' health, well-being and productivity $[11,12]$.

The micro-environment around the human body plays a major role for the heat and mass exchange between the body and the indoor environment and in exposure to indoor pollution [13]. A building occupant can be exposed to his/her own bio-effluents as well as to bio-effluents emitted from others. The importance of the separate and combined impact of the free convection flow and the flow of respiration on the exposure of bio-effluents released by an occupant's own body was the focus of the present study.

The Convective Boundary Layer (CBL) develops due to a temperature difference between the air surrounding the body and the surface of the body $[14,15]$. The CBL develops in the thermal plume above a person [16]. Gaseous and particulate pollutants generated from the body and in the immediate surroundings of the legs and trunk are entrained into the CBL of a seated person and are transported to the breathing zone [15, 17-19]. The concentration of bio-effluents from a seated body in the breathing zone is highest when it is released at the chest and lowest when it is emitted at the upper back or behind the chair. It increases when the room air temperature decreases or the body is inclined backward [20]. The exposure is also influenced by the position of a desk in front of the body, the chair and the clothing design. However, the cited studies did not take into account the respiratory flow and the impact of its interaction with the CBL on personal exposure.

Breathing is transient and most often consists of inhalation, then exhalation, followed by a pause. The dynamics of the inhalation flow very close to the nose and to the mouth are similar [21]. Large variations in the spread of exhaled flows occur between people [22].Exhalation generates jets with relatively high velocity, $1-2 \mathrm{~m} / \mathrm{s}[21,23,24]$, which depending on the head position can penetrate 


\section{Methods}

\subsection{Experimental setup and facilities}

Full-scale experiments were carried out in a climate chamber with dimensions of $4.7 \mathrm{~m}$ x $6.0 \mathrm{mx}$ $2.5 \mathrm{~m}$ (W x L x H). The chamber was ventilated by an upward piston airflow without recirculation, supplied from the entire floor area with an air velocity of less than $0.05 \mathrm{~m} / \mathrm{s}$. The upward piston flow of outdoor air ensured uniform air temperature and air velocity distribution in the chamber without recirculation of the tracer gases. The air was exhausted through a square opening $(0.38 \mathrm{x}$ $0.38 \mathrm{~m}^{2}$ ) in the ceiling (Fig. 1). The chamber had been constructed to ensure a mean radiant temperature equal to the room air temperature and negligible radiant temperature asymmetry.

A breathing thermal manikin with a realistic female body shape (size 38, $1.68 \mathrm{~m}$ height) was used to simulate the dry heat loss of a seated occupant [45]. The manikin had 23 body segments, each with individually controlled heat output. The surface temperature of the segments was controlled to be similar to the skin temperature of the body parts of an average human in a state of thermal comfort when exposed to the same room conditions and wearing the same clothing. The average surface temperature of the individual segments varied within the range of 32.0 to $34.8^{\circ} \mathrm{C}$. The manikin was seated behind a desk on an office chair (Fig. 2). The distance between the manikin's abdomen and the edge of the desk was $0.1 \mathrm{~m}$. The manikin and the desk were positioned in the centre of the chamber on a wooden plate $(2 \mathrm{~m} \times 1.21 \mathrm{~m})$ in order to prevent disturbance of the CBL. The seated manikin had a slightly inclined backward posture $\left(10^{\circ}\right.$ from the vertical axis) and its height in this position was $1.2 \mathrm{~m}$. The manikin was dressed in tight clothing comprising a t-shirt, tight-fitting trousers, underwear, socks and shoes (total thermal insulation together with the chair 0.55 clo). There was a short haired wig on the manikin's head.

Breathing was simulated by operating an artificial lung placed outside the chamber and connected by two plastic tubes ( $\varnothing 8 \mathrm{~mm}$ ) and connectors (situated on the lower back of the manikin) to its mouth and nose. It was possible to adjust the breathing frequency, the pulmonary ventilation rate and the temperature of the exhaled air. The nostrils were shaped so that they resembled those of an average person - round openings, each with a cross-sectional area of $38.5 \mathrm{~mm}^{2}$. The mouth of the manikin was slightly open, with an ellipsoidal opening with a cross-sectional area of $158 \mathrm{~mm}^{2}$. Jets emerging from the nostrils were deflected $40^{\circ}$ downwards from the horizontal [25]. 
the manikin's body. There were two openings per row and the distance between them was $0.135 \mathrm{~m}$. The VC was connected to an exhaust system which moved the exhausted air out of the chamber. A plastic mesh inside the ventilated cushion provided body support and allowed the exhaust air to move inside the cushion. The flow rate of air sucked through the $\mathrm{VC}$ was measured in the exhaust system with sensors Micatrone MFS C-80 (accuracy $\pm 3 \%$ of measured flow rate) connected to a differential pressure micro-manometer FCO510 (accuracy of $0.01 \mathrm{~Pa}[0.15 \times 10-5 \mathrm{psi}] \pm 0.25 \%$ of reading). The flow rate was controlled by adjusting the speed of a fan in the exhaust duct.

Personalized ventilation (PV) supplying clean air to the breathing zone of the thermal manikin via a Round Movable Panel (RMP) was used in this study to generate an external ventilation flow. The RMP had a circular outlet with diameter of $0.185 \mathrm{~m}$ and is a highly efficient air terminal device [46]. The RMP was installed on the desk in front of the manikin and positioned so that the distance between the outlet and the face of the manikin was $0.3 \mathrm{~m}$.

\subsection{Measuring procedure and instrumentation}

Two tracer gases, nitrous oxide $\left(\mathrm{N}_{2} \mathrm{O}\right)$ and carbon dioxide $\left(\mathrm{CO}_{2}\right)$, were used to simulate bio-effluent contaminants emitted below the clothing at the groin and armpits of the manikin, respectively. The tracer gases were continuously released through cylindrical porous ceramic air diffusers $(2.5 \mathrm{~cm}$ height and $\varnothing 1.2 \mathrm{~cm}$ ), ensuring that tracer gas was released with negligible initial momentum. The air diffusers were connected with tubes to gas cylinders located outside the chamber. The $\mathrm{N}_{2} \mathrm{O}$ and $\mathrm{CO}_{2}$ were not diluted with air and their emission rate was controlled by gas Rotameters and kept constant at $0.5 \mathrm{~L} / \mathrm{min}$ and $1.2 \mathrm{~L} / \mathrm{min}$ respectively.

$\mathrm{N}_{2} \mathrm{O}$ and $\mathrm{CO}_{2}$ concentrations were measured continuously at the manikin's chest $(3 \mathrm{~cm}$ away from the centre of the chest and $23 \mathrm{~cm}$ below the mouth), at the mouth (between the centres of the lips, at $0.5 \mathrm{~cm}$ distance) and at the nose (at the opening of the left nostril). Specially developed instruments (rapid meters) with a sampling rate of $4 \mathrm{~Hz}$ and a time constant of $0.8 \mathrm{~s}$ were used to measure tracer gas concentration. The rapid meters are based on a non-dispersive infrared absorption (NDIR) method and are described in detail by Kierat and Popiolek [47, 48]. Only instruments based on NDIR absorption method are fast enough to follow the respiration cycle. $\mathrm{CO}_{2}$ and $\mathrm{N}_{2} \mathrm{O}$ were therefore used in this study since they absorb infrared radiation very well and they are not toxic in the ranges used in these experiments. At each measurement location, a separate $\mathrm{N}_{2} \mathrm{O}$ and $\mathrm{CO}_{2}$ fast meter sampled the gas through a plastic tube $(\varnothing 3 \mathrm{~mm}$ and length $1 \mathrm{~m})$. In order to avoid too many tubes being attached to the manikin's face, the $\mathrm{N}_{2} \mathrm{O}$ and $\mathrm{CO}_{2}$ tubes at each sampling point joined into one tube using a Y-shaped connector. The resolution of the instruments was $1 \mathrm{ppm}$ and the expanded uncertainty was $\pm 20 \mathrm{ppm}$ ( $95 \%$ confidence level). Fourier transformation was applied for frequency correction of the signals from the instruments. Compensation of the data for the time needed for the $\mathrm{N}_{2} \mathrm{O}$ and $\mathrm{CO}_{2}$ samples to travel in the sampling tube from the measuring point to the fast meters was performed [48]. Two separate Innova 1312 photoacoustic gas analysers (accuracy $5 \%$ of the reading), each coupled to an Innova 1303 gas sampler, were used to measure the $\mathrm{N}_{2} \mathrm{O}$ and $\mathrm{CO}_{2}$ concentrations at $0.5 \mathrm{~m}$ above the manikin's head, and in the supply and total exhaust air [49]. 
Table 1. Studied cases - combinations between breathing mode, use of VC and PV.

\begin{tabular}{|c|c|c|c|c|c|c|c|c|c|}
\hline \multirow{2}{*}{ BC $[\mathrm{L} / \mathrm{s}]$} & \multicolumn{3}{|c|}{ NO BREATHING } & \multicolumn{4}{|c|}{$\begin{array}{l}\text { INHALATION NOSE/ } \\
\text { EXHALATION } \\
\text { MOUTH }\end{array}$} & \multicolumn{2}{|c|}{$\begin{array}{l}\text { INHALATION MOUTH/ } \\
\text { EXHALATION NOSE }\end{array}$} \\
\hline & OFF & 1.5 & 5.0 & OFF & 1.5 & 3.0 & 5.0 & OFF & 1.5 \\
\hline $\mathrm{PV}[\mathrm{m} / \mathrm{s}]$ & $\begin{array}{l}\text { OFF } \\
0.2 \\
0.4\end{array}$ & $\begin{array}{l}\text { OFF } \\
0.2\end{array}$ & $\begin{array}{l}\text { OFF } \\
0.2\end{array}$ & $\begin{array}{l}\text { OFF } \\
0.2 \\
0.4\end{array}$ & $\begin{array}{l}\text { OFF } \\
0.2\end{array}$ & OFF & $\begin{array}{l}\text { OFF } \\
0.2\end{array}$ & OFF & OFF \\
\hline
\end{tabular}

\subsection{Exposure assessment and data analyses}

Personal exposure was assessed by taking into account only the measured tracer gas concentrations during the inhalation period as shown in Fig. 3. First, signals measured at the mouth and nose were synchronized in time to each other using a cross-correlation function. Next, the exhalation periods were identified on the measured signal as cyclically repeating fragments with very low concentration (approx. $0 \mathrm{ppm}$ ). In this way, a binary signal of the whole breathing process was obtained giving the possibility to extract the inhalation periods. The concentrations measured at the nose (during "inhalation nose") and at the mouth (during "inhalation mouth") during 40 min steady state conditions were used in the analyses. Over 8192 samples of $\mathrm{N}_{2} \mathrm{O}$ and $\mathrm{CO}_{2}$ were obtained for all $2.5 \mathrm{~s}$ inhalation periods during one experimental condition. The measured data were used to calculate the mean, standard deviation (SD) and $95^{\text {th }}$ percentile of the concentration. The uncertainty of the tracer gas measurements was $20 \mathrm{ppm}$. During the experiments with no breathing function in operation, the mean, SD and $95^{\text {th }}$ percentiles of the concentrations measured at the nose and mouth were averaged in order to compare the results with the results obtained with different breathing modes.

The mean, SD and $95^{\text {th }}$ percentile of the concentrations measured for some of the conditions were normalised with the mean concentration of respective measurements performed without breathing, VC or PV. Normalized concentrations lower than "1" indicate that that inhaled pollutant concentration was reduced, i.e. reduced exposure. The excess concentration of $\mathrm{CO}_{2}$ over the background level of $480 \mathrm{ppm}$ was used as an assessment of exposure to armpit-emitted pollutants. The $\mathrm{N}_{2} \mathrm{O}$ concentration measured at the mouth and nose of the manikin was used as the criterion for exposure assessment to groin-emitted pollutants. 
the mouth (i.e. InM/ExN) and No breathing remained the same as in the case without source control. A residual effect of the breathing can be seen in the results shown in Fig. $4 \mathrm{~b}$ even with the $\mathrm{VC}$ in use.

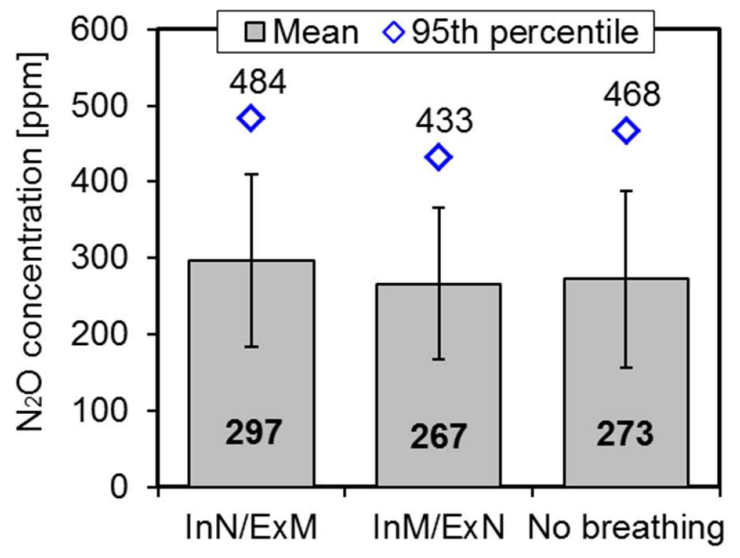

a)

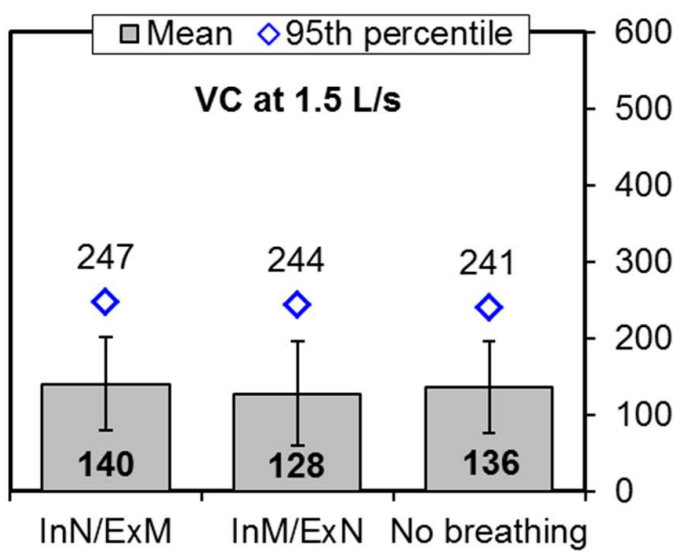

b)

Fig. 4 Impact of breathing mode on the exposure to pollution generated at the groin (a) and effect of breathing combined with the pollution source control i.e.VC performing at $1.5 \mathrm{~L} / \mathrm{s}$ (b). The SD is shown as error bars.
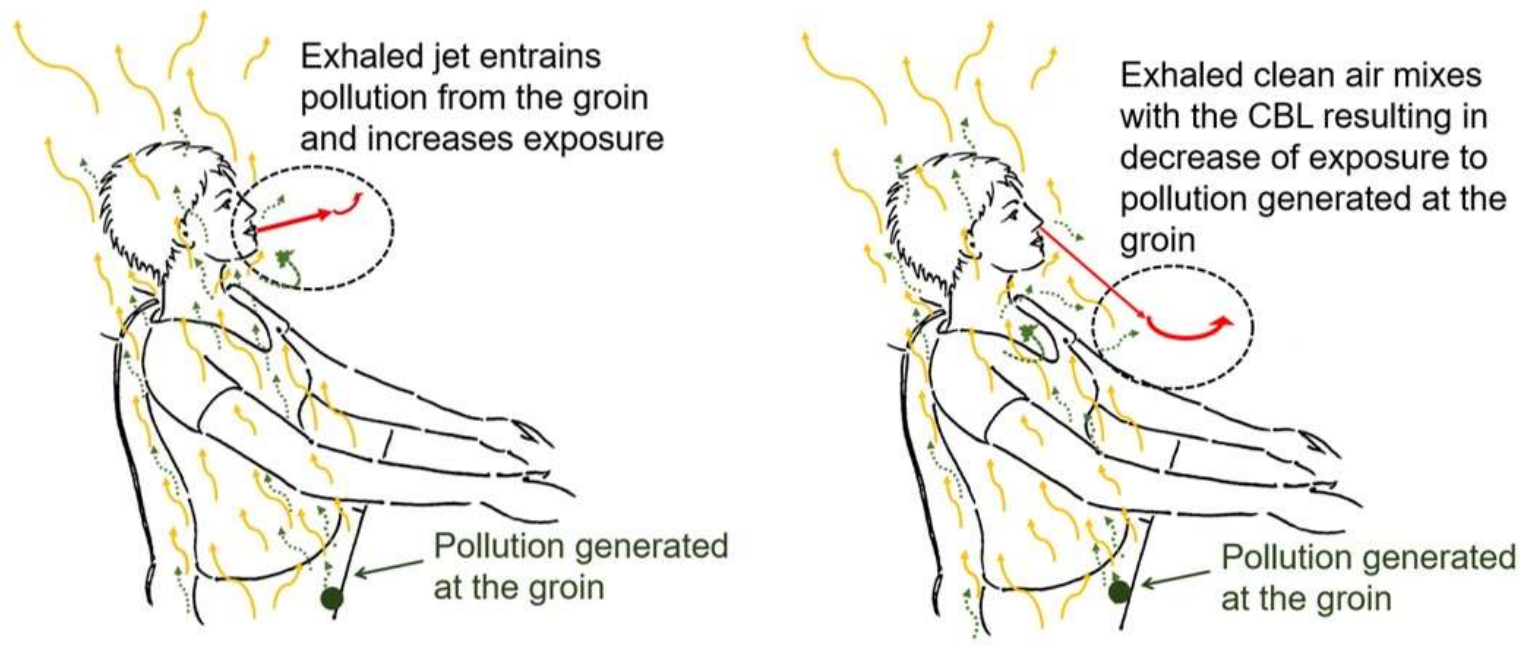

Fig. 5. Possible interaction of flow exhaled from nose or mouth and its impact on transport of pollution generated at the groin to the inhalation zone.

In contrast, when the pollution was released at the armpits, the mean and $95^{\text {th }}$ percentile of $\mathrm{CO}_{2}$ concentrations measured in the two breathing modes were substantially different (Fig. 6a). The 

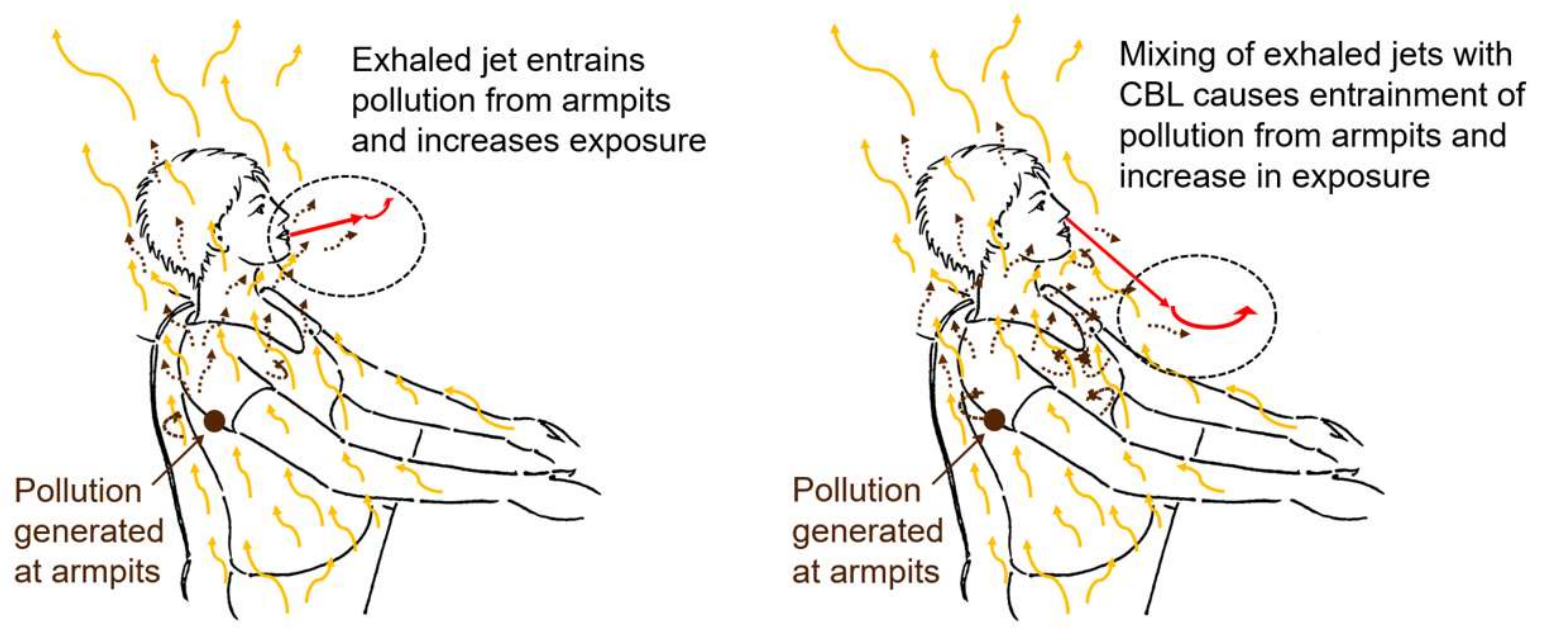

Fig. 7. Possible interaction of flow exhaled from nose or mouth and its impact on transport of pollution generated at the armpits to the inhalation zone.

\section{Impact of source control on exposure}

The importance of source control by local exhaust was studied with an extracted airflow of $0,1.5,3$ and $5 \mathrm{~L} / \mathrm{s}$ through the VC. The experiments were performed only for the case of inhalation nose/exhalation mouth/pause. It may be seen in Fig. 8 that the normalised mean and $95^{\text {th }}$ percentile values for $\mathrm{N}_{2} \mathrm{O}$ and $\mathrm{CO}_{2}$ decreased substantially when the airflow rate exhausted through the cushion increased. This means that the ventilated cushion was able to capture the emitted pollutants both at the groin and the armpits when the flow rate of the exhaust air was sufficiently high.

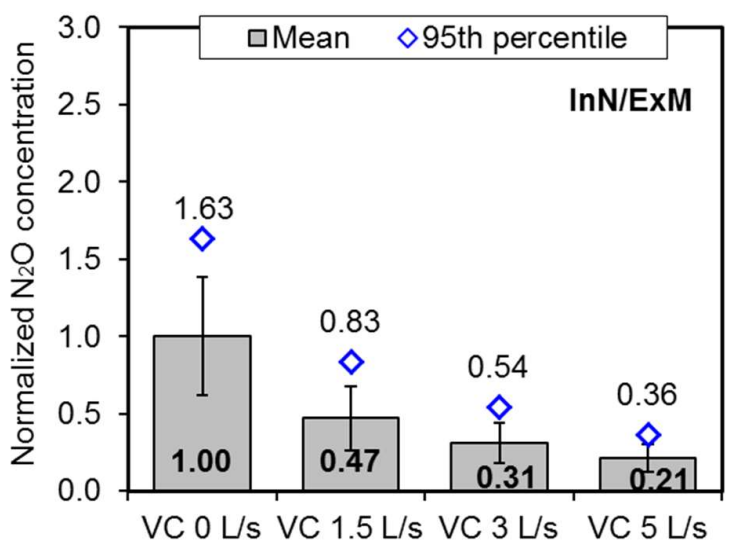

a)

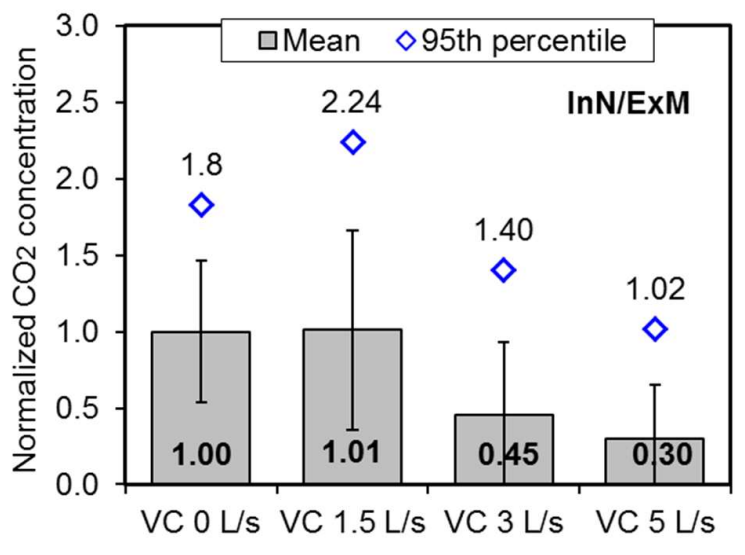

b)

Fig. 8. a) Normalised mean and $95^{\text {th }}$ percentile of $\mathrm{N}_{2} \mathrm{O}$ concentration (pollution from the groin) and b) Normalised mean and $95^{\text {th }}$ percentile of excess $\mathrm{CO}_{2}$ concentration (pollution from the armpits). The error bars show the normalised standard deviation. 


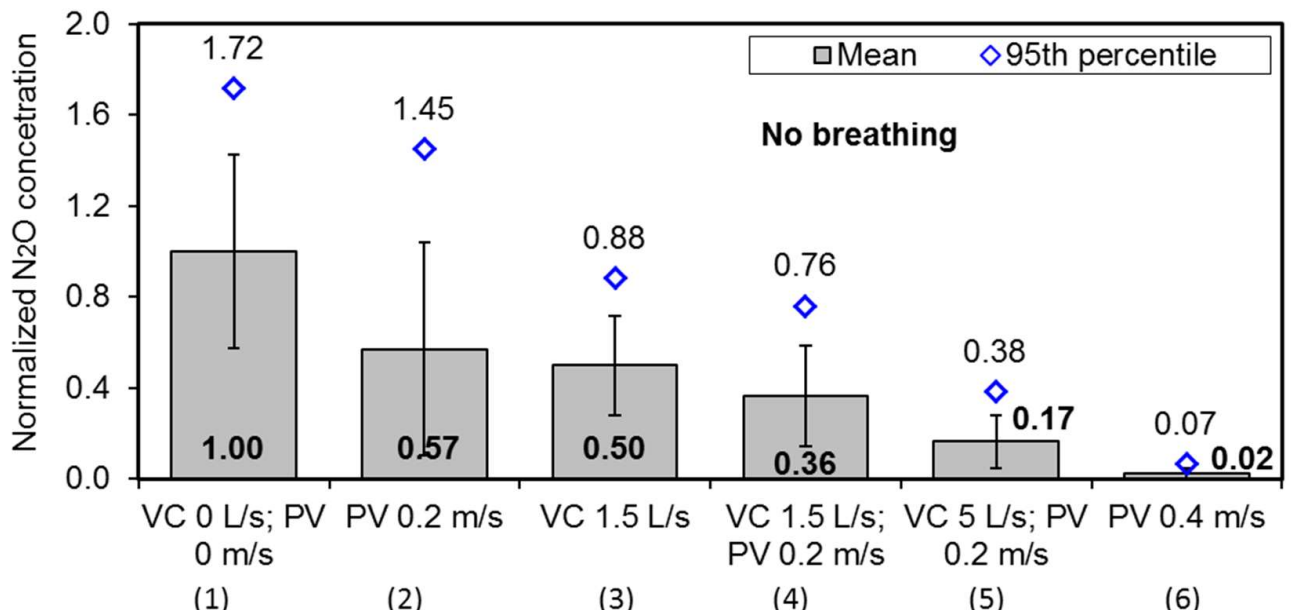

(1)

(2)

(3)

(4)

(5)

(6)

Fig. 10. Normalized $\mathrm{N}_{2} \mathrm{O}$ concentration with breathing OFF. Mean and $95^{\text {th }}$ percentile were normalised by dividing them by the mean concentration measured during VC $0 \mathrm{~L} / \mathrm{s}, \mathrm{PV} 0 \mathrm{~m} / \mathrm{s}$.
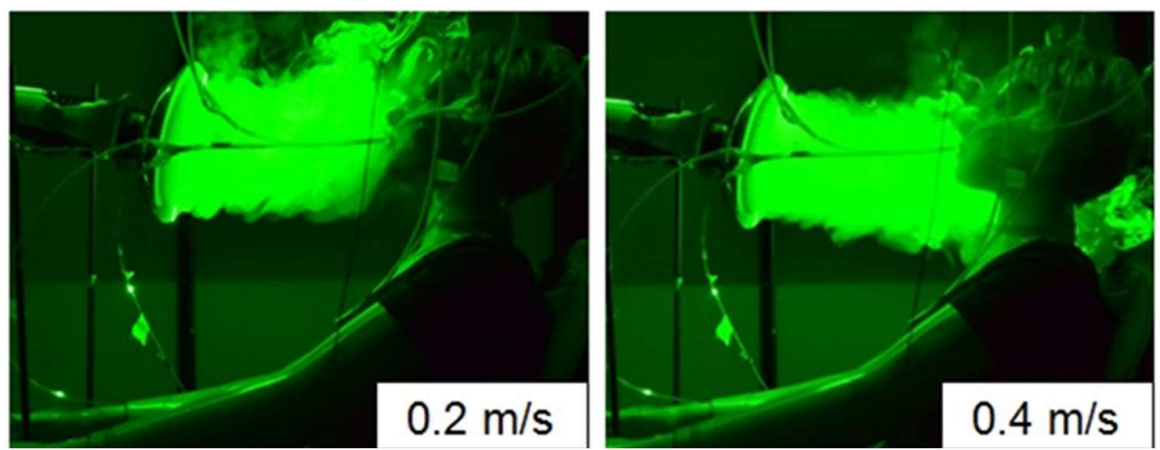

Fig. 11. Visualisation of the PV airflow supplied from in front at $0.2 \mathrm{~m} / \mathrm{s}$ and $0.4 \mathrm{~m} / \mathrm{s}$.

The results of the $\mathrm{CO}_{2}$ concentration measurements under the more complex flow interaction that included CBL, breathing and PV are shown in Fig. 12 for two target velocities of the personalised flow, namely 0.2 and $0.4 \mathrm{~m} / \mathrm{s}$. The PV applied at $0.2 \mathrm{~m} / \mathrm{s}$ did not work efficiently in providing clean air for breathing because it was too weak to completely penetrate the CBL. The clean PV supply air at $0.4 \mathrm{~m} / \mathrm{s}$ diluted the polluted CBL and decreased the exposure (Fig. 12). The results in Fig. 12 show that the mean $\mathrm{CO}_{2}$ concentrations were the same in the cases with PV regardless of whether breathing was or was not in operation. However, the $95^{\text {th }}$ percentiles and SDs were higher in the cases with breathing and PV compared to the corresponding cases without breathing. 
jet and the resulting increase in exposure was present when the $\mathrm{VC}$ was operated, even at $5 \mathrm{~L} / \mathrm{s}$ (Fig. 13 Bar 6). This was because the $\mathrm{VC}$ removed the $\mathrm{CO}_{2}$ from the back of the armpits, while the exhaled jet entrained the $\mathrm{CO}_{2}$ present at the front of the armpits.

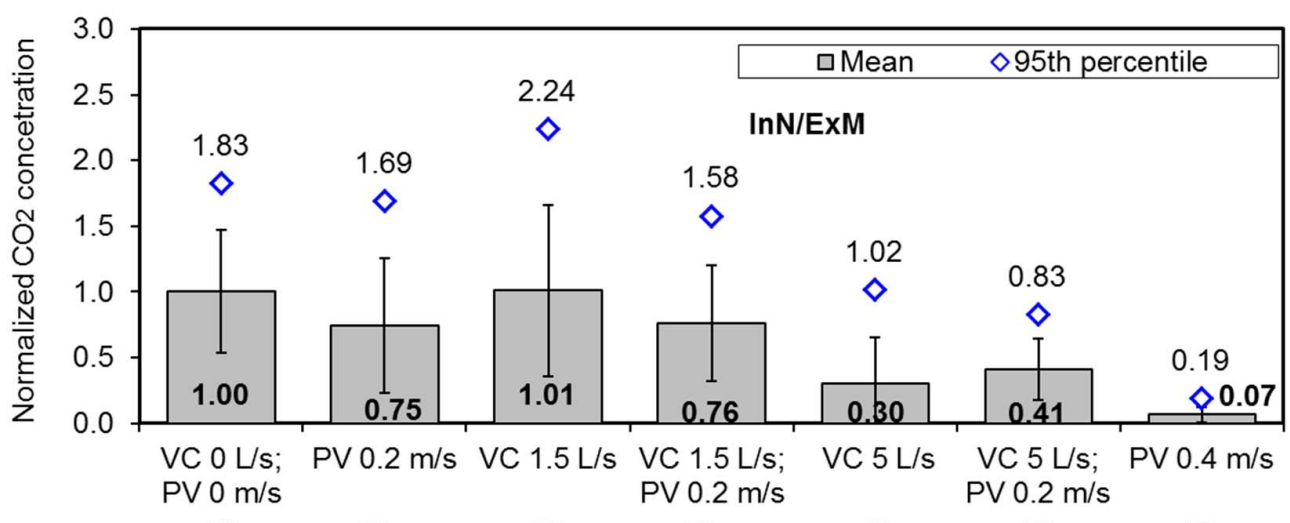
(1)
(2)
(3)
(4)
(5)
(6)
(7)

Fig. 13. Normalised $\mathrm{CO}_{2}$ concentration with breathing $\mathrm{ON}$. Mean and $95^{\text {th }}$ percentile were normalised by dividing them by the mean concentration measured during VC $0 \mathrm{~L} / \mathrm{s}, \mathrm{PV} 0 \mathrm{~m} / \mathrm{s}$.

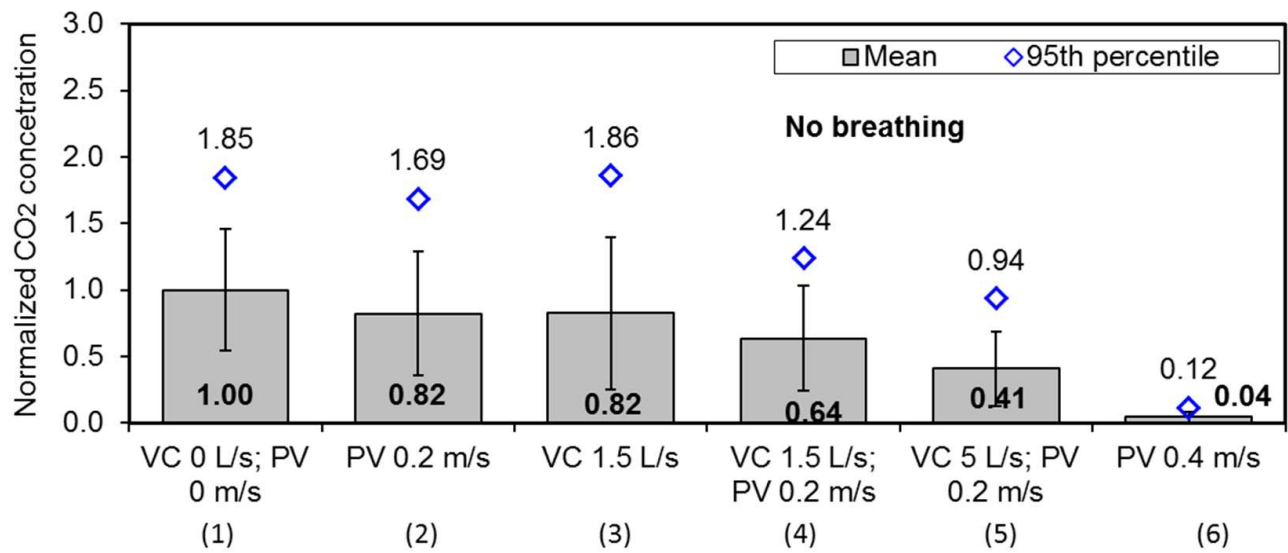

Fig. 14. Normalised $\mathrm{CO}_{2}$ concentration with breathing OFF. Mean and $95^{\text {th }}$ percentile were normalised by dividing them by the mean concentration measured during VC $0 \mathrm{~L} / \mathrm{s}, \mathrm{PV} 0 \mathrm{~m} / \mathrm{s}$.

\section{Discussion}

The present study focused on the exposure of a seated person to bio-effluents emitted by their own body. The results revealed that the airflow of exhalation increased exposure to gaseous pollution from body sites close to the breathing zone, such as the armpits. The exposure was higher for the breathing mode inhalation mouth/exhalation nose/pause compared to inhalation nose/exhalation mouth/pause. The interaction of the jet exhaled from the nose with the CBL generated mixing near the armpits, i.e. near the pollution source, and increased its transportation to the inhalation zone. This is an important observation, since assessment of exposure to bio-effluents without breathing 
breathing zone. The present results show that the combined use of a ventilated exhaust cushion and personalised ventilation may increase exposure under some conditions. Source control must be designed to remove both pollution and a proportion of the $\mathrm{CBL}$ air, to reduce its strength and make possible its penetration at the breathing zone by a lower velocity flow of clean air.

Another important finding of the present study is that the $95^{\text {th }}$ percentile of the concentration fluctuations was found to be much higher than the mean concentration. The question of which of these two parameters is more important for exposure assessment remains to be answered.

In this study for the first time the exposure to bio-effluents as a result of complex interaction of flows and local source control was investigated by tracer gas concentration measurements made only during the inhalation period. The results were obtained under a limited number of experimental conditions. Different body size and posture, head positioning, clothing design, breathing mode, breathing cycle, respiration rate and other individual difference between people, as well as table positioning, chair design, room air and radiant temperature, direction and characteristics of the ventilation flow in the vicinity of the body, etc. will affect airflow interaction in the breathing zone and thus exposure. For example, an increase of the room air temperature from $23^{\circ} \mathrm{C}$ to $28{ }^{\circ} \mathrm{C}$ will decrease the upward velocity of the CBL. In the case of exhalation from the nose, this may result in a decrease of exposure to pollution released at the groin, because the CBL transporting the pollution may not recover during the $1 \mathrm{~s}$ pause after exhalation. This must be studied because the flow interaction is complex and depends on the many factors listed above.

\section{Conclusion}

Concentration of own-body-released bio-effluents in inhaled air depends on a complex airflow interaction of the CBL, exhalation airflow (breathing mode) and locally applied ventilation flow towards the breathing zone.

The interaction of the exhaled flow with the CBL increases exposure to own-body-released pollution, especially when the site is close to the breathing zone.

Breathing does not influence exposure to gaseous pollutants emitted from the lower part of the body.

The use of mean tracer gas concentration in inhaled air is very different from its $95^{\text {th }}$ percentile. These two parameters will lead to different exposure assessments.

Well-designed source control can substantially reduce exposure to own-body-released pollution regardless of the flow interaction in the breathing zone.

The combined use of source control and personalised ventilation does not always reduce and may even increase exposure to own-body-released bio-effluents.

\section{Acknowledgements}


18. Rim D, Novoselac A, Morrison G. The influence of chemical interactions at the human surface on breathing zone levels of reactants and products. Indoor Air. 2009 Aug;19(4):324-34. 19. Gao NP, Niu JL. CFD study of the thermal environment around a human body: A review. Indoor and Built Environment. 2005 Feb;14(1):5-16.

20. Licina D, Melikov A, Sekhar C, Tham KW. Transport of gaseous pollutants by convective boundary layer around a human body. Science and Technology for the Built Environment. 2015 Nov;21(8):1175-86.

21. Haselton FR, Sperandio PGN. Convective exchange between the nose and the atmosphere. Journal of Applied Physiology. 1988 Jun;64(6):2575-81.

22. Gupta JK, Lin $\mathrm{CH}$, Chen QY. Characterizing exhaled airflow from breathing and talking. Indoor Air. $2010 \mathrm{Feb} ; 20(1): 31-9$.

23. Tang JLW, Nicolle AD, Klettner CA, Pantelic J, Wang LD, Bin Suhaimi A, et al. Airflow Dynamics of Human Jets: Sneezing and Breathing - Potential Sources of Infectious Aerosols. Plos One. 2013 Apr;8(4).

24. Xu C, Nielsen PV, Gong G, Liu L, Jensen RL. Measuring the exhaled breath of a manikin and human subjects. Indoor Air. 2015 Apr;25(2):188-97.

25. Melikov A, Kaczmarczyk J. Measurement and prediction of indoor air quality using a breathing thermal manikin. Indoor Air. 2007 Feb;17(1):50-9.

26. Villafruela JM, Olmedo I, Jose JFS. Influence of human breathing modes on airborne cross infection risk. Building and Environment. 2016 Sep;106:340-51.

27. Hyldgaard CE. Humans as a source of heat and air pollution. 4th International Conference on air distribution in rooms, Roomvent 1994; 1994; Cracow, Poland; 1994. p. 413-33.

28. Hoppe P. Temperatures of expired air under varying climatic conditons. International Journal of Biometeorology. 1981;25(2):127-32.

29. Ozcan O, Meyer KE, Melikov AK. A visual description of the convective flow field around the head of a human. Journal of Visualization. 2005;8(1):23-31.

30. Zhu SW, Kato S, Murakami S, Hayashi T. Study on inhalation region by means of CFD analysis and experiment. Building and Environment. 2005 Oct;40(10):1329-36.

31. Johnson AE, Fletcher B, Sanders CJ. Air movement around a worker in a low-speed flow field. Annals of Occupational Hygiene. 1996;40:57-64.

32. Bjorn E, Nielsen PV. Dispersal of exhaled air and personal exposure in displacement ventilated rooms. Indoor Air. 2002 Sep;12(3):147-64.

33. Zhang TF, Yin S, Wang SG. Quantify impacted scope of human expired air under different head postures and varying exhalation rates. Building and Environment. 2011 Oct;46(10):1928-36. 34. Marr D, Khan T, Glauser M, Higuchi H, Jianshun ZD. On Particle Image Velocimetry (PIV) Measurements in the Breathing Zone of a Thermal Breathing Manikin. ASHRAE Transactions; 2005; Denver, USA; 2005. p. 299-305.

35. Feng LY, Yao SY, Sun HJ, Jiang N, Liu JJ. TR-PIV measurement of exhaled flow using a breathing thermal manikin. Building and Environment. 2015 Dec;94:683-93.

36. Ge QJ, Li XD, Inthavong K, Tu JY. Numerical study of the effects of human body heat on particle transport and inhalation in indoor environment. Building and Environment. 2013 Jan;59:19.

37. Licina D, Melikov A, Sekhar C, Tham KW. Human convective boundary layer and its interaction with room ventilation flow. Indoor Air. 2015 Feb;25(1):21-35.

38. Laverge J, Spilak M, Novoselac A. Experimental assessment of the inhalation zone of standing, sitting and sleeping persons. Building and Environment. 2014 Dec;82:258-66. 